\title{
Political economy of food system reform
}

\author{
Policy packaging offers citizens better scope for assessing trade-offs in policy attributes and policymakers the \\ opportunity to make unpopular reforms, including those needed to achieve healthy and sustainable food system \\ transformation, more palatable to their constituents.
}

\section{Danielle Resnick}

$\mathrm{P}$ olicymakers are increasingly urged to implement reforms to foster sustainable food systems. Yet, the political economy of such a transition towards greater sustainability is rarely examined, despite its importance in determining when and why policy change is possible. Fesenfeld and colleagues provide a major contribution to the analysis of the political economy of food system transformation in this issue of Nature Food by examining citizens' preferences for different combinations of policy interventions to reduce the environmental footprint of the food system ${ }^{1}$. Almost 5,000 citizens from China, Germany and the US took part in conjoint experiments to examine preferences for policy packages aimed at reducing consumption and production of meat and fish products. Using conjoint experiments is a real strength of the study since respondents typically overestimate their personal commitment to a policy option if asked about it in isolation; when considering multiple policy bundles, however, they assess trade-offs in policy attributes and indicate more clearly to policymakers how much citizen support each option would be likely to receive.

The policy bundles tested in the study vary according to whether they involve supply-side changes on behalf of producers and distributors of food or demand-side changes aimed at shifting consumer behaviour. Specifically, six different policy instruments were considered: a new tax on meat and fish products, rules about providing a minimum share of vegetarian meals in public cafeterias, information campaigns, discounts for citizens who purchase vegetarian alternatives, a reduction in subsidies for meat and fish producers, and stricter animal farming standards. Respondents were randomly presented with different packages of these instruments, along with a scenario on how to earmark tax revenues, that varied at different levels of stringency.

Fesenfeld and colleagues find that citizens tend to prefer policy bundles that are more stringent on supply-side interventions, such as stricter organic animal farming standards for producers, and less so on the demandside, such as taxes. Nonetheless, there were interesting variations across countries. A majority of Chinese respondents, for instance, were broadly supportive of a 15 per cent tax on meat and fish products as well as rules for public cafeterias. Both of these though were opposed by a large share of US and German respondents. In all three countries, a majority supported halving producer subsidies - a supply-side cost - and being exposed to more frequent information campaigns.

The authors chose China, Germany, and the US for their analysis because they are among the world's largest producers and consumers of meat and fish and have a major impact on the global environment and food system. Thus, if there are bundles of policy options that citizens in these countries would support, there could be significant impacts on planetary health. While that is true, it would be extremely valuable to expand such research to low- and middle-income countries where there is evidence of rising obesity linked to growing incomes and increased consumption of ultra-processed foods and animal-sourced foods ${ }^{2-4}$. To proactively address this growing burden, it would be useful for government decision makers in such contexts to have a greater understanding of which bundles of policies - including subsidies for producers of nutrient-dense foods, taxes on sugarsweetened beverages, and mandated shifts in the food environment - citizens would support to improve dietary diversity and nutrition-sensitive agriculture.

More broadly, the authors highlight the value of policy packaging, which, in their words, "may open up room for political manoeuvre and enable policymakers to adopt environmental policies that are both strong (and thus effective) and politically feasible." If policymakers could keep in mind the main takeaway from this paper, which is that policy packaging can help make unpopular reforms more palatable to a diverse array of constituents, then there would be scope for greater optimism about consumer support for achieving healthy and sustainable food system transformation.

\section{Danielle Resnick}

Development Strategy and Governance Division, International Food Policy Research Institute (IFPRI), Washington DC, USA.

e-mail:d.resnick@cgiar.org

Published online: 17 March 2020

https://doi.org/10.1038/s43016-020-0049-2

References

1. Fesenfeld, L. P., Wicki, M., Sun, Y. \& Bernauer, T. Nat. Food https://doi.org/10.1038/s43016-020-0047-4 (2020).

2. Ecker, O. in Agriculture for Improved Nutrition: Seizing the Momentum (eds Fan, S. et al.) Ch. 8 (CAB International, 2019).

3. NCD Risk Factor Collaboration (NCD-RisC) Lancet 390 2627-2642 (2017).

4. Popkin, B. M. \& Gordon-Larsen, P. Int. J. Obes. Relat. Metab. Disord. 28, S2-S9 (2004). 